\title{
Screening of Depression in Infertile Females Attending Infertility Clinic in Egypt: A Cross-Sectional Study
}

\author{
Marwa Mostafa Ahmed*, Nagwaa Eid Saad \\ Department of Family Medicine, Cairo University, Cairo, Egypt
}

Email address:

marwamostafa@kasralainy.edu.eg (M. M. Ahmed)

\section{To cite this article:}

Marwa Mostafa Ahmed, Nagwaa Eid Saad. Screening of Depression in Infertile Females Attending Infertility Clinic in Egypt: A Cross-Sectional Study. European Journal of Preventive Medicine. Vol. 3, No. 6, 2015, pp. 184-187. doi: 10.11648/j.ejpm.20150306.14

\begin{abstract}
Background: Infertility can have an extravagated impact on the psychological wellbeing of the couple and subsequently affect the marital relationship and the quality of life. Objective: To screen for depression in infertile female attending infertility clinic and to determine the severity of depression in relation to duration of infertility and other socio-demographic characteristics in an Egyptian setting. Methods: This cross-sectional descriptive study was conducted from June 2014 to December 2014 in the infertility clinic in Kasr Al-Ainy hospital. Three hundred infertile females were screened for depression using the Arabic version of the Patient Heath Questionnaire (PHQ-9). Results: According to (PHQ-9), 62.3\% of the studied infertile females suffer from moderate to severe depression. The score of PHQ-9 was inversely proportionate to both the duration of marriage $(\mathrm{P}$ value $=0.038$, person correlation:-0.12) and duration of infertility $(\mathrm{P}$ value $=0.025$, person correlation: -0.13 ) and was directly proportionate to age of studied females ( $P$ value $=0.032$, person correlation: 0.124$)$, their educational level ( $\mathrm{P}$ value $=0.000$, person correlation: 0.312$)$ and number of trial of assisted reproductive technique $(\mathrm{P}$ value $=0.001$, person correlation: 0.189), and these data were statistically significant. Conclusion: A large percentage of Egyptian infertile females suffer from depression. And this highlights the challenging need for providing individualized bio-psychosocial care for all infertile Egyptian females.
\end{abstract}

Keywords: Infertility, Depression, Mental Health, Egypt

\section{Introduction}

Infertility is considered a public health issue worldwide affecting $3.5 \%$ to $16.7 \%$ of the childbearing population in developed countries and $6.9 \%$ to $9.3 \%$ in less-developed countries [1]. On individual level, the inability to conceive is considered a personal tragedy and a heartbreaking experience for the couple and the whole family [2].

Infertility is of particular concern in Africa as human reproduction is highly valued in African societies. Motherhood in Africa is often the only way for women to enhance their status within their family and community. In some communities, the stigma of childlessness places the infertile women at risk of serious social and emotional consequences [3]. Infertility has also an economic consequence; as beside the cost of treatment, the loss of income through the lack of working children and the loss of old age security increase the economic burden of the infertile couple. Unfortunately, infertile females in the developing countries perceived infertility as a 'medical and social poverty trap' [4].

Infertility can have an extravagated impact on the psychological wellbeing of the couple and subsequently affect the marital relationship and the quality of life of a couple. Anxiety, depression, and psychosomatic complication can affect infertile couples [3, 5].Many infertile females experience depressive symptoms, including hopelessness, and guilt. Subset of these females meet the criteria for major depressive disorder, including depressed mood, sleep and appetite disturbance, fatigue, psychomotor retardation, poor concentration, and suicidal ideation or even attempt [6]. Therefore, counseling to reduce depression, anxiety and stress should be given routinely to all infertile women beside their treatment for infertility [7].

In our study, we have made an attempt to screen for depression in infertile female attending infertility clinic in Kasr Al-Ainy hospital and also to determine the severity of depression in relation to duration of infertility and other socio-demographic characteristics in an Egyptian setting. 


\section{Methods}

\subsection{Study Setting and Population}

This cross-sectional descriptive study was conducted from June 2014 to December 2014 in the infertility clinic in kasr al ainy hospital which is considered one of the largest public hospitals in Egypt. In order to be enrolled, respondents should have met the definition of infertility defined as the inability of a sexual active non-contraceptive using woman to have a live birth after 12 or more months of regular sexual intercourse. Any female diagnosed with secondary infertility was excluded from the study.

\subsection{Sampling}

Using Epi Info 7, sample size was calculated using the following input: prevalence of depression among infertile females was $62 \%$ according to a study done by Alhassan et al. in 2014 [8], significant level of 0.05 and power of $90 \%$, the total sample size was 255 participants. The sample size was increased to include 300 infertile females.

\subsection{Data Collection}

\subsubsection{The First Step}

Following consent, participants completed an interview that includes demographic data and medical history including: duration of infertility, investigations done, primary cause of infertility and whether trial of assisted reproductive technique was done. All study participants were asked if they feel safe in their marriage.

\subsubsection{The Second Step}

Screening for depression was done using the Arabic version of the Patient Heath Questionnaire (PHQ-9) [9]. The questionnaire consists of nine questions which focus on different symptoms of depressive disorder. The PHQ-9 scores each of the 9 DSM-IV criteria as "0" (not at all) to "3" (nearly every day). A PHQ-9 score $>$ or $=10$ had a sensitivity of $88 \%$ and a specificity of $88 \%$ for major depression. PHQ- 9 scores of $5-9,10-14,15-19$, and $>20$ represented mild, moderate, moderately severe, and severe depression [10].

\subsection{Statistical Analysis}

The collected data were statistically analyzed using statistical Package for Social Sciences (SPSS) version 16. Data were statistically described in terms of Mean, \pm Standard Deviation $( \pm$ SD) or Frequencies (Number of cases) and percentages when appropriate. For comparing categorical data, Chi square $\left(\mathrm{X}^{2}\right)$ test was performed. Fisher Exact test was used instead when the expected frequency is less than 5 . $\mathrm{P}$ value less than 0.05 was considered statistically. Pearson's correlation coefficient was used to assess the correlation between the quantitative variables. Correlation was mild if correlation coefficient $(\mathrm{r})$ was less than 0.3 , moderate if $0.7 \geq$ $\mathrm{r} \geq 0.3$, powerful if more than 0.7 .

\subsection{Ethical Approvals}

Ethical approval was obtained from the Research Committee of Cairo University. Written consents were taken from all participants after explaining the objectives of the work. Confidentiality was guaranteed on handling data base and questionnaires forms according to Helsinki declaration of biomedical ethics.

\section{Results}

Three hundred infertile females were included in the study; their age ranged from 17 to 40 . The mean age was 27.72 years $( \pm 5.12)$. Around $10 \%$ of participants were illiterate, while $33 \%$ were university graduate. More than half of them were housewives and $37.7 \%$ of them were living in extended families.

According to (PHQ-9) 6\% of the studied infertile females were severely depressed and $21 \%$ of them suffered from moderate severe depression (Figure 1). There was significant relation between severity of depression and age of studied females, type of family, occupation, and duration of marriage and infertility, feeling safe in their marriage, whether their husband performed any investigations or not, primary cause of infertility and trial of assisted reproductive technique. (Table 1).

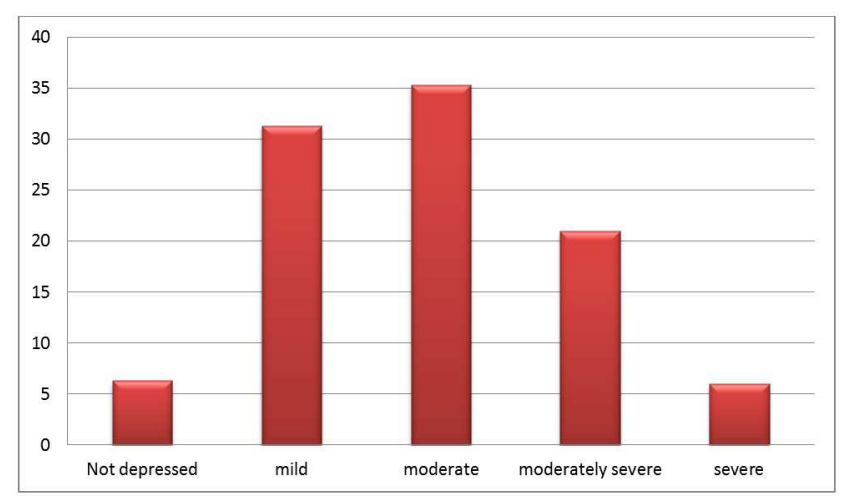

Figure 1. Degree of depression among infertile females.

The score of PHQ-9 was inversely proportionate to both the duration of marriage $(P$ value $=0.038$, person correlation: -0.12 ) and duration of infertility ( $\mathrm{P}$ value $=0.025$, person correlation: $-0.13)$ and was directly proportionate to age of studied females ( $\mathrm{P}$ value $=0.032$, person correlation: 0.124$)$, their educational level $(\mathrm{P}$ value $=0.000$, person correlation: 0.312$)$ and number of trial of assisted reproductive technique ( $\mathrm{P}$ value $=0.001$, person correlation: 0.189 ), and these data were statistically significant.

\section{Discussion}

In Egypt, like any other developing countries, children are highly valued for cultural, social and economic reasons. Therefore, the diagnosis of infertility places a huge burden on the infertile couple especially the female who is usually the one who take all the blame for not having children. These societal pressures have a negative impact on the psychological 
state of the infertile female. This was evident in our study where $62.3 \%$ of the studied infertile females suffer from moderate to severe depression. This finding is consistent with the work of Alhassan et al. in 2014 [8] were $62 \%$ of infertile females suffered from depression in Ghana. This percent is lower than the findings of Ahmed et al. in 2014 [5], where 26\% and $74 \%$ of the recruited infertile females suffered mild to moderate and moderate to severe depression respectively. This percent is higher than other studies done in Riyad (53.8\%) [11] and Iran (40.8\%) [12].This difference in the prevalence of depression among the studied infertile females may be due to the difference of perception of infertility among different cultures. In addition, the discrepancy between the used instruments may account for this variation.

Table 1. Relation between severity of depression and different variables.

\begin{tabular}{|c|c|c|c|c|c|c|c|c|c|c|c|}
\hline & \multicolumn{2}{|c|}{ No $(n=42)$} & \multicolumn{2}{|c|}{ Mild (n=59) } & \multicolumn{2}{|c|}{ Moderate $(\mathrm{n}=77)$} & \multicolumn{2}{|c|}{ Moderately severe $(n=69)$} & \multicolumn{2}{|c|}{ Severe $(n=53)$} & \multirow[t]{2}{*}{ p value } \\
\hline & $\mathbf{N}$ & $\%$ & $\mathbf{N}$ & $\%$ & $\mathbf{N}$ & $\%$ & $\mathbf{N}$ & $\%$ & $\mathbf{N}$ & $\%$ & \\
\hline \multicolumn{12}{|l|}{ Age } \\
\hline$<21$ & 0 & 0 & 14 & 56 & 8 & 32 & 3 & 12 & 0 & 0 & \multirow{3}{*}{$0.000 *$} \\
\hline $21-30$ & 7 & 3.8 & 54 & 29.7 & 80 & 44 & 31 & 17 & 10 & 5.5 & \\
\hline$>30$ & 12 & 12.9 & 26 & 28 & 18 & 19.4 & 29 & 31.2 & 8 & 8.6 & \\
\hline \multicolumn{12}{|l|}{ Type of family } \\
\hline Extended & 5 & 4.4 & 46 & 40.7 & 41 & 36.3 & 18 & 15.9 & 3 & 2.7 & \multirow[t]{2}{*}{$0.019^{*}$} \\
\hline Nuclear & 14 & 7.5 & 48 & 25.7 & 65 & 34.8 & 45 & 24.1 & 15 & 8 & \\
\hline \multicolumn{12}{|l|}{ Occupation } \\
\hline Housewife & 15 & 8.9 & 56 & 33.3 & 73 & 43.5 & 16 & 9.5 & 8 & 4.8 & \multirow{2}{*}{$0.000^{*}$} \\
\hline Employed & 4 & 3 & 38 & 28.8 & 33 & 25 & 47 & 35.6 & 10 & 7.6 & \\
\hline \multicolumn{12}{|c|}{ Duration of marriage } \\
\hline $0-5$ & 7 & 3.9 & 57 & 31.8 & 59 & 33 & 38 & 21.2 & 18 & 10.1 & \multirow{4}{*}{$0.000^{*}$} \\
\hline$>5-10$ & 0 & 0 & 25 & 28.4 & 44 & 50 & 19 & 21.6 & 0 & 0 & \\
\hline$>10-15$ & 12 & 38.7 & 11 & 35.5 & 3 & 9.7 & 5 & 16.1 & 0 & 0 & \\
\hline$>15$ & 0 & 0 & 1 & 50 & 0 & 0 & 1 & 50 & 0 & 0 & \\
\hline \multicolumn{12}{|c|}{ Duration of infertility } \\
\hline $0-5$ & 7 & 3.4 & 68 & 32.7 & 73 & 35.1 & 42 & 20.2 & 18 & 8.7 & \multirow{4}{*}{$0.001 *$} \\
\hline$>5-10$ & 7 & 10.6 & 14 & 21.2 & 30 & 45.5 & 15 & 22.7 & 0 & 0 & \\
\hline$>10-15$ & 5 & 20 & 12 & 48 & 3 & 12 & 5 & 20 & 0 & 0 & \\
\hline$>10-15$ & 0 & 0 & 0 & 0 & 1 & 100 & 0 & 0 & 0 & & \\
\hline \multicolumn{12}{|c|}{ Feeling safe in marriage } \\
\hline never & 7 & 17.9 & 4 & 10.3 & 25 & 64.1 & 3 & 7.7 & 0 & 0 & \multirow{5}{*}{$0.000^{*}$} \\
\hline rare & 0 & 0 & 1 & 2.3 & 28 & 65.1 & 11 & 25.6 & 3 & 7 & \\
\hline sometimes & 0 & 0 & 12 & 2.4 & 0 & 0 & 31 & 62 & 7 & 14 & \\
\hline often & 0 & 0 & 8 & 100 & 0 & 0 & 0 & 0 & 0 & 0 & \\
\hline always & 12 & 7.5 & 69 & 43.1 & 53 & 33.1 & 18 & 11.3 & 8 & 5 & \\
\hline \multicolumn{12}{|c|}{ Husband perform any investigation } \\
\hline no & 19 & 6.5 & 91 & 31.1 & 102 & 34.8 & 63 & 21.5 & 18 & 6.1 & \multirow{2}{*}{0.454} \\
\hline yes & 0 & 0 & 3 & 42.9 & 4 & 57.1 & 0 & 0 & 0 & 0 & \\
\hline \multicolumn{12}{|c|}{ Responsible for infertility } \\
\hline wife & 16 & 7 & 85 & 37 & 79 & 34.3 & 40 & 17.4 & 10 & 4.3 & \multirow{4}{*}{$0.003 *$} \\
\hline husband & 1 & 20 & 0 & 0 & 1 & 20 & 3 & 60 & 0 & 0 & \\
\hline Wife and husband & 2 & 3.3 & 8 & 13.3 & 23 & 38.3 & 19 & 31.7 & 8 & 13.3 & \\
\hline Didn't know & 0 & 0 & 1 & 20 & 3 & 60 & 1 & 20 & 0 & 0 & \\
\hline \multicolumn{12}{|c|}{ Trial of Assisted reproductive technique } \\
\hline yes & 5 & 8.6 & 10 & 17.2 & 17 & 29.3 & 26 & 44.8 & 0 & 0 & \multirow{2}{*}{$0.000^{*}$} \\
\hline no & 14 & 5.8 & 84 & 34.7 & 89 & 36.8 & 37 & 15.3 & 18 & 7.4 & \\
\hline
\end{tabular}

In our study, there was positive correlation between depression score and age. Also Ogawa et al. in 2011 [13] and Alhassan et al. in 2014 [8] found that as age increased, participants exhibited a greater tendency towards depression. The perception of infertile females that their chances of having a baby decrease with age, put them under psychological pressure which could have contributed to this high score of depression as noted in the current study. In addition, there was positive correlation between depression score and educational level. On the other hand, Alhassan et al. [8] reported a negative correlation with educational level as women who attained higher education had lower depression scores. This discrepancy may be due to the difference in the educational level between the participant females in both studies.
It was found that the score of depression is inversely proportional to the duration of marriage and hence the duration after the diagnosis of infertility is made. Results of different studies about relationship of duration of infertility depression were not similar. Ahmed et al. in 2014 [5] reported a direct relation between depression score and duration of infertility. This was not the case in the study done by Ogawa et al. in 2011 [13] where there was no relation between the duration of infertility and depression score. The difference between these studies may be due to the fact that the infertile female in our study suffered from longer duration of infertility. In addition, it may be due to cultural difference, as in Egypt, the societal pressure reaches its peak during the early years of marriage. Moreover, the coping mechanisms of infertile females can differ from country to country. 


\section{Conclusion}

Infertility resulted in social stigmatization for Egyptian infertile females, placing them at risk of serious social, emotional and psychological consequences. A large percentage of them suffer from depression. And this highlights the challenging need for providing individualized biopsychosocial care for all infertile Egyptian females.

\section{References}

[1] Boivin J, Bunting L, Collins JA, Nygren KG. International estimates of infertility prevalence and treatment-seeking: potential need and demand for infertility medical care. Hum. $\begin{array}{llll}\text { Reprod, } 2007 ; & 22 & \text { (6): } & 1506-1512 .\end{array}$ doi:10.1093/humrep/dem046.

[2] Greil AL, Slauson-Blevins K, Julia McQuillan J. The experience of infertility: A review of recent literature. Sociol Health Illn. 2010; 32(1): 140-162. doi:10.1111/j.1467-9566.2009.01213.x.

[3] Dhont N, van de Wijgert J, Coene G, Gasarabwe A, Temmerman M. 'Mama and papa nothing': living with infertility among an urban population in Kigali, Rwanda. Human Reproduction, 2011; 26(3):623-629. doi:10.1093/humrep/deq373.

[4] Dyer SJ and Patel M. The economic impact of infertility on women in developing countries - a systematic review. FVV in OBGYN, 2012;4 (2): 102-109.

[5] Ahmed A, Fathima N, Vishwakarma SK, Khan A A, Ramakrishna P, Souza RD, Rozatti R. Psychological evaluation of couples attending the infertility clinic in a tertiary care, teaching hospital. Int.J.Curr.Res.Aca.Rev.2014; 2(2):133-147.
[6] Catapano LA. Depression in Women with Infertility. The Female Patient, 2010; 35:20-22.

[7] Kousalya K, Sanjeeva Reddy N, Uma Maheswara Reddy C, Jayashree K. Depression, Anxiety And Stress Among Infertile Women And The Impact Of Counseling On These Levels. Innovative Journal of Medical and Health Science 2013; 3(3):110 - 112 .

[8] Alhassan A, Ziblim A, Muntaka S. A survey on depression among infertile women in Ghana. BMC Women's Health, 2014, 14:42. Available from http://www.biomedcentral.com/1472-6874/14/42.

[9] Spitzer R, Williams J, Kroenke K: Patient health questionnair (PHQ) screeners. Pfizer Inc; Available from:http://www.phqscreeners.com. Accessed 12/2014

[10] Kroenke K, and Spitzer RL. The PHQ-9: A New Depression Diagnostic and Severity Measure. Psychiatr ann 2002; 22(9):1-7.

[11] Al-Homaidan HT. Depression among Women with Primary Infertility attending an Infertility Clinic in Riyadh, Kingdom of Saudi Arabia: Rate, Severity, and Contributing Factors. International Journal of Health Sciences, 2011. Vol.5(2):108-115.

[12] Ramezanzadeh F, Aghssa MM, Abedinia N, Zayeri F, Khanafshar N, Shariat M, Jafarabadi M: A survey of relationship between anxiety, depression and duration of infertility. BMC Womens Health 2004, 4(1):9. doi:10.1186/1472-6874-4-9.

[13] Ogawa M, Takamatsu K, Horiguchi F.Evaluation of factors associated with the anxiety and depression of female infertility patients. BioPsychoSocial Medicine, 2011; 5:15. Available from http://www.bpsmedicine.com/content/5/1/15. 